\title{
Effect of HIV Housing Services on Engagement in Care and Treatment, New York City, 2011
}

\author{
Arpi S. Terzian - Mary K. Irvine - Laura M. Hollod • \\ Sungwoo Lim · John Rojas • Colin W. Shepard
}

Published online: 29 January 2015

(c) Springer Science+Business Media New York 2015

\begin{abstract}
The federal Housing Opportunities for Persons with AIDS (HOPWA) program addresses housing needs of low-income persons living with HIV/AIDS (PLWHA). The New York City (NYC) Department of Health and Mental Hygiene oversees 22 HOPWA contracts for over 2,400 clients, and manages the NYC HIV Registry. HOPWA clients $(N=1,357)$ were matched to a random $20 \%$ sample of other PLWHA $(N=13,489)$. Groups were compared on HIV care retention, viral suppression, and rebound. HOPWA clients were, on average, 3 years younger and more likely to be concurrently diagnosed with HIV and AIDS. While HOPWA clients were more likely to be retained in care $(94$ vs. $82 \%$; $\mathrm{mOR}=2.97,95 \% \mathrm{CI}$ 2.35-3.74), they were no more likely to achieve suppression ( 84 vs. $86 \% ; m$ mOR $=0.85,95 \% 0.70-1.03$ ) and were more likely to rebound ( 11 vs. $7 \%$; $\mathrm{mOR}=1.45$; $95 \%$ CI 1.10-1.91). HIV care retention does not fully translate to virologic suppression in this low-income service population.
\end{abstract}

Keywords Public health surveillance · Housing · Epidemiology · HIV infection/prevention and control . Engagement in care

Preliminary results were presented at an oral presentation at the American Public Health Association 140th Annual Meeting and Exposition in October 2012 (Session \#3227.0).

A. S. Terzian $(\bowtie) \cdot$ M. K. Irvine · L. M. Hollod ·

S. Lim · J. Rojas - C. W. Shepard

New York City Department of Health and Mental Hygiene,

Queens, New York, NY 11101, USA

e-mail: aterzian@health.nyc.gov

\section{Introduction}

Public funds are spent each year to address the needs of homeless and unstably housed persons living with HIV/ AIDS (PLWHA). In fiscal year 2012, \$332 million dollars were granted nationally to Housing Opportunities for Persons with AIDS, also known as HOPWA, a housing assistance program that was established by the US Department of Housing and Urban Development (HUD) through the National Affordable Housing Act of 1990. The New York City (NYC) Department of Health and Mental Hygiene (DOHMH), the designated HOPWA grantee for NYC, received \$55 million dollars in fiscal year 2012 to administer, manage, and reimburse the delivery of housingrelated supportive services [1]. In keeping with the goals of the National HIV/AIDS Strategy (NHAS) and recent recommendations from the US Department of Health and Human Services (DHHS), these HIV housing-related services are aimed at increasing low-income individuals' access to health care and essential resources for managing illness, and thus reducing disparities in HIV health outcomes [1-6].

The HIV care continuum, representing sequential stages of care engagement from testing/diagnosis to successful treatment/viral suppression, is a widely adopted framework for measuring HIV health outcomes [7, 8]. 'Near perfect' adherence to antiretroviral treatment (ART) is required to ensure success at the final stage of the continuum (viral suppression), which is key both to individual health and survival and to the prevention of onward HIV transmission at the population level [9]. Homeless or unstably housed PLWHA face particular barriers to achieving and maintaining optimal HIV care outcomes, in that (1) they tend to have lower CD4 cell counts and higher viral loads at diagnosis (key biomarkers of HIV disease progression and 
predictors of mortality) [10]; (2) they have higher rates of comorbid infections like hepatitis, tuberculosis, and Pneumocystis carinii pneumonia than those who are stably housed [11]; (3) they are less likely to adhere even with access to ART because immediate subsistence needs like food and shelter are not met [5, 12, 13]; and (4) providers may not prescribe ART as readily to unstably housed individuals, due to concerns that those patients will not be adherent [14, 15]. Despite substantial federal and local investments in HIV-related housing services and in promoting HIV care and treatment engagement, few studies have examined the effects of housing-related services on outcomes along the HIV care continuum.

We aimed to assess HIV-related care outcomes among PLWHA enrolled in the 22 NYC DOHMH-administered HOPWA (hereafter "NYC HOPWA") programs in 2011, and compare enrollees' outcomes to those of a demographically and clinically similar group from the larger HIVinfected population in NYC. We compared retention in care, viral suppression (any and durable), and viral rebound between NYC HOPWA clients and PLWHA not enrolled in NYC HOPWA programs ("other PLWHA"), controlling for group differences using propensity score matching. We hypothesized that enrollment in NYC HOPWA programs would be associated with better care outcomes.

Given the substantial public investment in HIV-related housing programs, particularly in NYC and in the context of strained resources for a growing HIV population [16], there is a clear need for evidence of housing program effectiveness. This analysis represents a first stage of evaluation of the impact of the NYC HOPWA program overall. This work will help to direct further analyses and ultimately inform program refinements, priority-setting and resource allocation in the broader domain of publicly funded, HIV-related health and social services.

\section{Methods}

NYC HOPWA Program. The HOPWA program in NYC offers three types of housing-related supportive services: rental assistance (RA), housing placement assistance (HPA), and supportive permanent housing (SPH) [2]. RA consists of cash subsidies to establish or maintain permanent housing. HPA consists of services that help individuals locate, acquire, finance, and maintain permanent housing, but HPA does not provide ongoing rental assistance. HPA can include activities such as service plan development, escorts to appointments, apartment inspections, advocacy, and coordination of services to ensure that clients secure permanent housing. SPH, the most comprehensive of the three, provides affordable housing that is intended to be long-term [2, 17]. It also provides comprehensive supportive services designed to enhance management of HIV and other comorbid conditions and improve self-sufficiency. Support services include but are not limited to service plan development, advocacy, escorts to appointments, health promotion and education, mental health counseling, and substance use counseling [2, 12, 13, 17, 18]. To be eligible for NYC HOPWA services, individuals must be $\mathrm{HIV}$-infected and residing in $\mathrm{NYC}$, with a gross household income that does not exceed $50 \%$ of the median family income per HUD listings by family size for NYC, and a documented need for housing financial assistance [1-3]. Although levels of support vary by service type, all NYC HOPWA clients are assigned to a case manager responsible for at least quarterly assessment and reporting to NYC DOHMH of clients' engagement in HIV primary care.

\section{Ethics Statement}

The NYC DOHMH adheres to safeguards to ensure confidentiality and privacy of individuals with HIV. Analysis of HIV surveillance data is authorized for the purpose of epidemiologic monitoring, as specified in the New York Codes, Rules and Regulations, Title 10, Part 63 (Revised 2/12) [19].

Evaluation of HOPWA service programs is outside the purview of institutional review boards (IRBs), provided that access to identifying information is limited to staff who help manage the HOPWA program under evaluation, and that analyses are secondary, based on routinely collected data for program management purposes [1]. For these reasons, this analysis was exempt from human subjects review requirements.

\section{Data Sources}

\section{NYC HIV Surveillance Registry}

The population-based NYC HIV Surveillance Registry ('the Registry') is continuously updated with new laboratory results (i.e., CD4 counts and viral loads) and vital status for all persons diagnosed with HIV infection or AIDS, as defined by the Centers for Disease Control and Prevention (CDC), and reported to the NYC DOHMH [20]. Name-based reporting of AIDS diagnoses was mandated by New York State (NYS) law in 1983, followed by namebased reporting of HIV in 2000 [19]. All data were drawn from the Registry as of September 30, 2012.

\section{NYC HOPWA Program Data}

Starting in January 2008, the NYC DOHMH began receiving named, client-level data from NYC HOPWA-funded agencies, through a secure, web-based reporting system. Clientlevel data collected for NYC HOPWA include full identifiers 
(such as first and last name), demographic characteristics, enrollment information, type of services received and selfreported data on clinical and HIV treatment histories. HOPWA data included in this analysis were reported to the NYC DOHMH as of February 2013.

\section{Other NYC HIV Program Data}

The NYC DOHMH also has access to named data from additional HIV-related benefits and services programs funded through the NYC DOHMH. Enrollment data from these programs had already been merged into the Registry dataset used for this analysis.

\section{Merged Dataset}

NYC HOPWA clients were matched to the Registry dataset using a deterministic algorithm that incorporates first and last name, date of birth, and social security number [21]. The matched dataset included surveillance data such as age, race/ ethnicity, and concurrent diagnosis (i.e., an AIDS diagnosis within 31 days of an HIV diagnosis), along with programmatic data such as date of enrollment and type of services received.

\section{Eligibility Criteria}

To be eligible for inclusion in the analysis as an NYC HOPWA client, an individual had to: (1) be at least 18 years of age and diagnosed with HIV infection before January 2011, (2) be reported to the NYC DOHMH by September 2012, (3) receive NYC HIV medical care in 2010 (a proxy for residency in NYC), (4) be presumed living as of the end of December 2011 (based on vital statistics incorporated into the Registry), and (5) be enrolled in NYC HOPWA as of January 1, 2011, in any one of the three HOPWA service categories. Evidence of medical care in 2010 was defined as having at least one viral load (VL) or CD4 count laboratory test result reported to the Registry in 2010. To be eligible for inclusion in the analysis as a comparison group member, an individual had to meet the same inclusion criteria detailed above, except that they could not be enrolled in NYC HOPWA programs at any time in 2010 or 2011 . From this eligible subset of PLWHA, a random sample of $20 \%$ was selected to represent the final comparison group.

Analytic Variables

\section{Outcome Variables}

We used surveillance-based laboratory data on VL and CD4 tests to assess engagement in HIV care and treatment
[22] during calendar year 2011. Results from these laboratory data represent clinical health status, while dates of test results represent the timing of care. Four outcomes were constructed to describe engagement in care and treatment: retention in care, viral suppression (two measures - any and durable), and viral rebound. Based on a measure proposed in the NHAS, retention in care was defined as $\geq 2$ lab tests occurring $\geq 3$ months apart over a 12 -month period $[4,22,23]$. For the outcomes of viral suppression and rebound, VL results were categorized as either suppressed $(\leq 200$ copies $/ \mathrm{mL})$ or unsuppressed ( $>200$ copies/mL) [24]. Two measures of viral suppression were constructed: (1) any suppression (having $\geq 1$ suppressed VL in the 12-month period, among those with at least $1 \mathrm{VL}$ ); and (2) durable suppression (having $\geq 2$ consecutive suppressed VLs at least 2 weeks apart in the 12-month period, among those with at least 2 VLs) [25, 26]. Following the DHHS standard, viral rebound was defined as having an unsuppressed VL following two consecutive suppressed VLs at least 2 weeks apart in the 12-month period, among those with at least 3 VLs [26, 27].

\section{Exposure Variable}

Enrollment in NYC HOPWA was the primary exposure variable of interest, and was defined as being enrolled from 2010 into the start of calendar year 2011, the follow-up observation period for outcome measures. Qualifying enrollments could begin anytime between 2008 and 2010, and span any number of days in 2011, as long as they continued into 2011. We counted as NYC HOPWA exposure a qualifying enrollment in any one (or more) of the 22 NYC HOPWA programs. The NYC HOPWA sample included enrollees (index clients) as well as any HIV-infected adult dependents who may have directly or indirectly received benefits (such as housing) from the index client's enrollment.

\section{Covariates}

For the construction of propensity scores estimating the probability of NYC HOPWA exposure, we relied upon nine variables that each significantly predicted HOPWA enrollment and at least one outcome of interest (at the alpha 0.05 level) in logistic regression models (data not shown): HIV transmission risk category at diagnosis, age at the end of 2011, race/ethnicity, sex, neighborhood-level poverty (based on ZIP code at HIV or AIDS diagnosis), country of origin, history of concurrent AIDS diagnosis, last CD4 count as of December 31, 2010 (a proxy for immunologic status), and enrollment in other local HIV public assistance programs not administered by NYC DOHMH. Concurrent diagnosis, a marker of delayed 
testing, represents a missed opportunity for timely engagement in care and treatment. Based on CDC's classification system, HIV transmission risk was categorized as injection drug use (IDU), sex between male partners (MSM), heterosexual sex, or other/unknown.

\section{Data Analysis}

\section{Propensity Score Matching}

PLWHA who are enrolled in NYC HOPWA are expected to systematically differ from other PLWHA on measured and unmeasured baseline characteristics that relate to need or eligibility for NYC HOPWA services. In randomized controlled trials (RCTs), the groups would be assigned at random to treatment conditions, so that analyses of treatment effects would not be confounded by these differentially distributed characteristics [28]. In observational studies, propensity score matching functions to balance baseline characteristics between two groups in order to isolate and estimate the effect of treatment [29]. Groups of subjects with the same score are presumed equally likely to be in the treated and untreated groups. Matching by propensity score is then used to estimate the effect of treatment status on the outcome of interest, ensuring that the probability of receiving treatment is statistically similar across groups [29].

In this analysis, NYC HOPWA clients were matched for comparison to a random sample of other PLWHA. A $20 \%$ sample of the total eligible comparison group was selected because of its minimal computational burden for the estimation of propensity scores and its close approximation to precision estimates when $100 \%$ of non-HOPWA PLWHA were included in an exploratory analysis (data not shown) [30]. After calculating a propensity score for each person, we performed optimal full matching, a method that allows one or multiple treated subjects to be matched to one or multiple untreated subjects [31]. Optimization attempts to match sets of people such that any two propensity scores within a set have the smallest possible 'distance' (the smaller the distance, the more similar an exposed individual is to the unexposed individual) [28]. The Optmatch package in $\mathrm{R}$ (R Foundation, Vienna, Austria) was used to construct matched sets of NYC HOPWA clients and other PLWHA based on propensity scores [28]. We observed 620 matched sets, where more than half of the matched sets $(51 \%)$ were between one exposed and one unexposed person; the remaining sets consisted of multiple persons in the exposed and/or unexposed groups. We evaluated the extent to which optimal full matching balanced differences between exposed and unexposed groups by examining whether propensity score matching decreased the difference in percentages across covariates. If the difference became less than 0.1 , which was considered to be a negligible difference in a covariate between two groups on average $[32,33]$, we concluded that the desired covariate balance between two groups was achieved, and therefore matching was effective (data not shown).

\section{Summary Statistics and Logistic Regressions}

To estimate the effect of NYC HOPWA enrollment (as of the start of 2011) on retention, viral suppression (any and durable), and viral rebound in 2011, we computed four conditional logistic regression models accounting for the matched sets. These models are referenced throughout as 'matched analyses,' and are represented in the resulting matched odds ratios (mOR) and $95 \%$ confidence intervals (CI). For comparison, we also computed logistic regression models of each of the four outcomes on NYC HOPWA enrollment alone; these models, not conditioned on matched sets, are referenced throughout as 'unmatched analyses.' Summary statistics on unmatched sets were computed using Cochran-Mantel-Haenszel $\chi^{2}$ tests for general associations for categorical variables and independent $t$ tests for continuous variables, to assess sociodemographic differences by NYC HOPWA enrollment status. SAS 9.2 software (SAS Institute Inc., Cary, NC) was used to produce summary statistics and logistic regression models.

\section{Results}

Of the 1,533 PLWHA enrolled in NYC HOPWA as of the start of 2011, 1,357 (89\%) met the remaining eligibility criteria and were matched to a $20 \%$ random sample of eligible other PLWHA reported to the Registry $(N=13,489$; Fig. 1$)$. NYC HOPWA clients were, on average, 3 years younger than other PLWHA (median age in NYC HOPWA was 45 years), and more likely to be nonHispanic black (57 vs. $44 \%$ ), foreign-born (38 vs. $18 \%$ ), previously incarcerated (18 vs. $12 \%)$ and concurrently diagnosed with HIV and AIDS (12 vs. $9 \%$ ). In both groups, just under two-thirds had a history of an AIDS diagnosis. NYC HOPWA clients were also more likely to be enrolled in other local HIV public assistance programs not administered by the NYC DOHMH (67 vs. $45 \%$ ) and live in the highest poverty neighborhoods (32\% residing in neighborhoods where $30-100 \%$ of residents live below the poverty line vs. $27 \%$ ). In addition, NYC HOPWA clients were less likely to be male (59 vs. $70 \%$ ), report MSM transmission risk ( 30 vs. $37 \%$ ), live in Manhattan at time of diagnosis (19 vs. $27 \%$ ), or have higher CD4 counts at the end of 2010 (44\% had CD4 counts $\geq 500$ cells $/ \mathrm{mm}^{3}$ vs. 


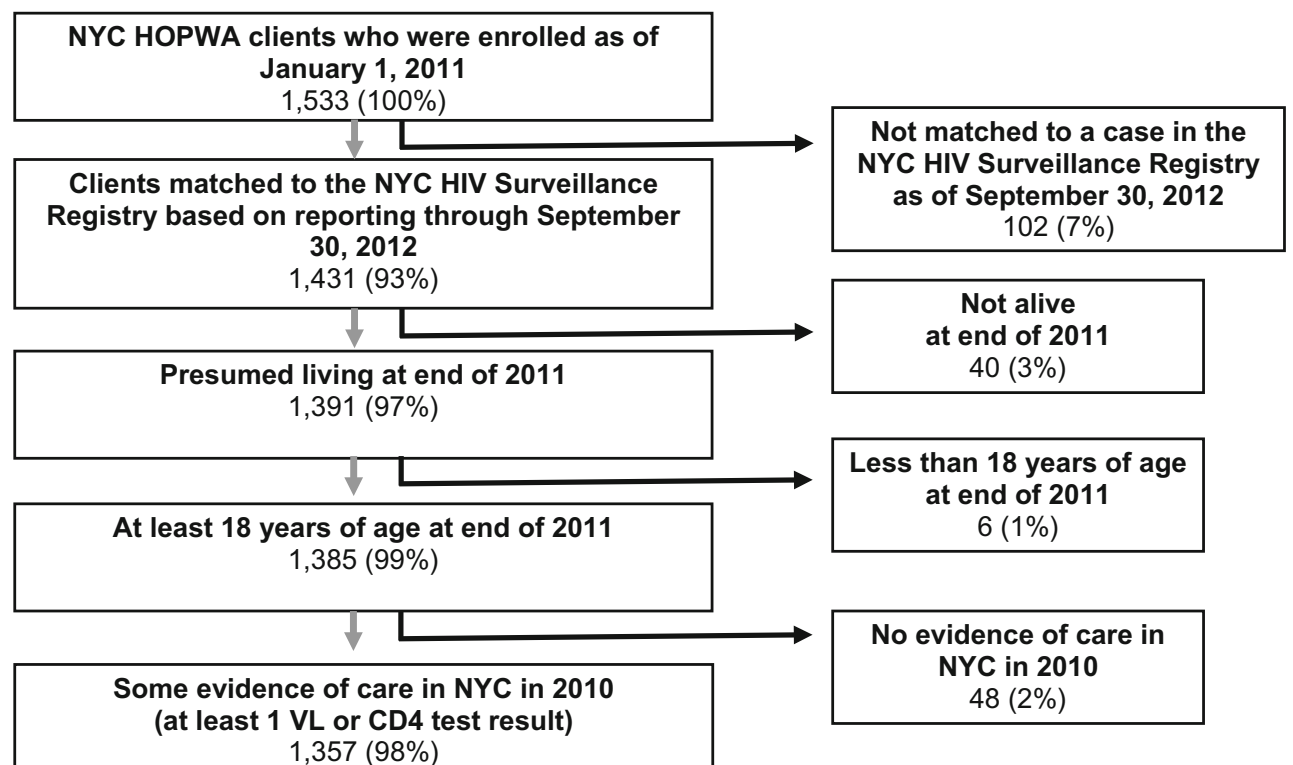

Fig. 1 Flow chart of NYC DOHMH-administered HOPWA program client eligibility for analysis

$49 \%)$. These differences were statistically significant at the alpha 0.05 level (Table 1).

Regarding program exposure prior to the start of followup, NYC HOPWA clients had been continuously enrolled in NYC HOPWA for a median of 1.58 years from the start of 2008 (the earliest point of electronic reporting of HOPWA client-level information to the DOHMH) to the start of 2011. Nearly half of HOPWA enrollees were enrolled in SPH, one-third in HPA, and one-fifth in RA. Clients enrolled in HPA had been enrolled for the least amount of time, with a median duration of 0.33 years prior to the start of follow-up (January 1, 2011), compared to RA and SPH clients, who were enrolled for a median duration of about 3 years prior to the start of follow-up (Table 1). Regarding continued enrollment during the follow-up period (calendar year 2011), the median number of days enrolled was 365 for SPH, 365 for RA, and 151 for HPA. Transition to other service provision programs during this follow-up period was not tracked, though clients in any NYC HOPWA program, and particularly those in the shortterm HPA program, may have transitioned from their initial NYC HOPWA services program as of the start of 2011 to other ongoing housing-related support services (administered by NYC DOHMH or another agency).

NYC HOPWA clients were more likely to be retained in care (94 vs. $82 \%$; see Table 2), with nearly three times the odds of retention compared with other PLWHA in matched analyses $(\mathrm{mOR}=2.97,95 \%$ CI 2.35-3.74; Table 3). Seventy-eight percent $(78 \%)$ of NYC HOPWA clients experienced viral suppression, compared to $82 \%$ of other PLWHA (Table 2). The proportion of NYC HOPWA clients and other PLWHA achieving durable viral suppression was similar (84 vs. $86 \%$; Table 2). While NYC HOPWA clients appeared to have statistically significant decreased odds of viral suppression (any or durable) in unmatched analyses, associations did not persist in matched analyses (mOR for any $=0.92,95 \%$ CI $0.72,1.08$ and mOR for durable $=0.85,95 \%$ CI 0.70, 1.03; Table 3). However, NYC HOPWA clients were more likely to experience viral rebound (11 vs. $7 \%$; Table 2), and this association persisted in both unmatched and matched analyses $(\mathrm{mOR}=1.45 ; 95 \%$ CI $1.10,1.91$; Table 3$)$.

\section{Discussion}

Compared to other PLWHA, NYC HOPWA clients had significantly higher retention in care in 2011. The high probability of being retained in HIV medical care is not entirely surprising, since HOPWA clients are all actively enrolled in HIV supportive services (and specifically services that require routine assessment for HIV primary care engagement) [1, 12, 34]. Both groups were substantially higher on retention than the $45 \%$ in 2009 estimated from 13 jurisdictions nation-wide [23].

The proportion of NYC HOPWA PLWHA who were virally suppressed (among those with at least one VL test in the year) is similar to the nationwide average of $77 \%$ in $2010[23,35]$ and higher than the citywide average of $75 \%$ in 2011 [36]. Despite their greater retention in care, NYC HOPWA clients were no more likely than other PLWHA to achieve any or durable viral suppression. In both unmatched and matched analyses, NYC HOPWA clients were more likely than the other, similar NYC PLWHA to 
Table 1 Selected characteristics of NYC DOHMH-administered HOPWA program clients and a random sample of other NYC PLWHA

\begin{tabular}{|c|c|c|}
\hline & $\begin{array}{l}\text { NYC HOPWA clients } \\
N=1,357 \\
N(\%)\end{array}$ & $\begin{array}{l}\text { Random sample of other PLWHA } \\
N=13,489 \\
N(\%)\end{array}$ \\
\hline \multicolumn{3}{|l|}{ Risk } \\
\hline MSM & $401(30)$ & $4,923(37)$ \\
\hline Heterosexual $^{\mathrm{a}}$ & $405(30)$ & $2,923(22)$ \\
\hline IDU & $239(18)$ & $2,221(16)$ \\
\hline Other/Unknown & $312(23)$ & $3,422(25)$ \\
\hline \multicolumn{3}{|c|}{ Age in years as of December 31, 2011} \\
\hline Mean & 44.9 & 47.6 \\
\hline Median [IQR] & $45[38-52]$ & $48[41-55]$ \\
\hline \multicolumn{3}{|l|}{ Sex } \\
\hline Male & $795(59)$ & $9,508(70)$ \\
\hline Female & $562(41)$ & 3,981 (30) \\
\hline \multicolumn{3}{|l|}{ Race/ethnicity ${ }^{\mathrm{b}}$} \\
\hline Non-Hispanic Black & $773(57)$ & $5,949(44)$ \\
\hline Hispanic & $520(38)$ & $4,476(33)$ \\
\hline Non-Hispanic White & $50(4)$ & $2,756(21)$ \\
\hline Other & $14(1)$ & $308(2)$ \\
\hline \multicolumn{3}{|c|}{ Borough of residence at diagnosis ${ }^{c}$} \\
\hline Bronx & $259(19)$ & $2,644(20)$ \\
\hline Brooklyn & $343(25)$ & $3,017(22)$ \\
\hline Manhattan & $257(19)$ & $3,637(27)$ \\
\hline Queens & $252(19)$ & $1,632(12)$ \\
\hline Staten Island & $61(4)$ & $197(1)$ \\
\hline Outside of NYC & $41(3)$ & $680(5)$ \\
\hline Unknown/Missing & $144(11)$ & $1,682(13)$ \\
\hline \multicolumn{3}{|l|}{ Neighborhood-level poverty ${ }^{\mathrm{d}}$} \\
\hline 0 to $<10 \%$ & $60(4)$ & $1,118(8)$ \\
\hline 10 to $<20 \%$ & $299(22)$ & 2,582 (19) \\
\hline 20 to $<30 \%$ & $260(19)$ & $2,111(16)$ \\
\hline 30 to $100 \%$ & $433(32)$ & $3,667(27)$ \\
\hline Missing & $305(23)$ & 4,011 (30) \\
\hline \multicolumn{3}{|l|}{ Country of origin } \\
\hline US & $690(51)$ & $8,331(62)$ \\
\hline Foreign ${ }^{\mathrm{e}}$ & $520(38)$ & $2,419(18)$ \\
\hline Unknown & $147(11)$ & $2,739(20)$ \\
\hline \multicolumn{3}{|l|}{ History of incarceration ${ }^{\mathrm{f}}$} \\
\hline Yes & 248 (18) & $1,640(12)$ \\
\hline No & $1,004(74)$ & $10,347(77)$ \\
\hline Missing & $105(8)$ & 1,502 (11) \\
\hline \multicolumn{3}{|c|}{ Enrolled in other HIV public assistance programs in 2011} \\
\hline Yes & $907(67)$ & $6,094(45)$ \\
\hline No & $450(33)$ & $7,395(55)$ \\
\hline \multicolumn{3}{|l|}{ Provider type at diagnosis } \\
\hline Outpatient facility & $312(23)$ & $3,836(28)$ \\
\hline Inpatient facility & $3,558(26)$ & $553(41)$ \\
\hline Screening/diagnostic/referral & $52(4)$ & $389(3)$ \\
\hline Other & $41(3)$ & $217(2)$ \\
\hline Missing & 399 (29) & $5,489(41)$ \\
\hline
\end{tabular}


Table 1 continued

\begin{tabular}{|c|c|c|}
\hline & $\begin{array}{l}\text { NYC HOPWA clients } \\
N=1,357 \\
N(\%)\end{array}$ & $\begin{array}{l}\text { Random sample of other PLWHA } \\
N=13,489 \\
N(\%)\end{array}$ \\
\hline \multicolumn{3}{|l|}{ Concurrent HIV/AIDS diagnosis $^{\mathrm{g}}$} \\
\hline Yes & $160(12)$ & $1,202(9)$ \\
\hline No & $1,197(88)$ & $12,287(91)$ \\
\hline \multicolumn{3}{|l|}{ AIDS as of December 31, 2011} \\
\hline$N(\%)$ & $860(63)$ & $8,426(62)$ \\
\hline Median $[\mathrm{IQR}]$ year of diagnosis & 2003 [1999-2007] & $2002[1997-2006]$ \\
\hline \multicolumn{3}{|l|}{ Total number of unique test dates in 2011} \\
\hline$N(\%)$ & $1,324(98)$ & $12,328(91)$ \\
\hline Mean [median, IQR] & $3.4[3.0,3-4]$ & $3.0[3.0,2-4]$ \\
\hline \multicolumn{3}{|l|}{ Last CD4 count in $2010\left(\right.$ cells $\left./ \mathrm{mm}^{3}\right)$} \\
\hline 0-199 & $181(13)$ & $1,598(12)$ \\
\hline $200-349$ & 235 (17) & $2,215(16)$ \\
\hline $350-499$ & $335(25)$ & $2,915(22)$ \\
\hline$\geq 500$ & $601(44)$ & $6,587(49)$ \\
\hline Missing & $5(<1)$ & 174 (1) \\
\hline Duration of enrollment as of $12 / 31 / 2010$, years (median [IQR]) & $1.58[0.4-3.0]$ & N/A \\
\hline \multicolumn{3}{|l|}{ Housing type } \\
\hline Housing placement assistance & $415(31)$ & N/A \\
\hline Rental assistance & $366(27)$ & \\
\hline Supportive permanent housing & $576(42)$ & \\
\hline \multicolumn{3}{|l|}{ Duration of enrollment by housing type, years (median [IQR]) } \\
\hline Housing placement assistance & $0.33[0.1-0.7]$ & N/A \\
\hline Rental assistance & $2.91[1.3-3.0]$ & \\
\hline Supportive permanent housing & $2.67[1.3-3.0]$ & \\
\hline
\end{tabular}

Numbers in bold denote statistical significance at the 0.05 level. Data as reported to the NYC DOHMH by September 30, 2012

PLWHA persons living with HIV/AIDS, HOPWA Housing Opportunities for Persons with AIDS, VL viral load, NYC New York City, MSM men who have sex with men, $I D U$ injection drug users, Med median, $I Q R$ interquartile range

${ }^{a}$ This transmission risk category includes heterosexual sex with an HIV-infected person, an injection drug user, or a person who has received blood products. For females only, heterosexual risk also includes sex with a male and at least one of the following: history of commercial sex work, multiple male sex partners, sexually transmitted infections, crack/cocaine use, sex with a bisexual male, probable heterosexual transmission as noted in a medical chart, or negative history of injection drug use

${ }^{\mathrm{b}}$ Due to small numbers, persons reporting more than one race, Native Americans or Alaskan Natives, Hawaiian Natives, Asians, and Pacific Islanders were classified as 'Other' race/ethnicity

${ }^{c}$ Borough of residence refers to the residence at HIV diagnosis for persons living HIV (non-AIDS) or residence at AIDS diagnosis for persons living with AIDS

${ }^{\mathrm{d}}$ Neighborhood-level poverty, based on ZIP code at HIV or AIDS diagnosis, defined as percent of residents with incomes below $100 \%$ of the Federal Poverty Level per American Community Survey Census 2000

e Foreign refers to people known to have been born outside the US or US dependencies

${ }^{\mathrm{f}}$ Data on history of incarceration are incomplete

g HIV cases concurrently diagnosed with AIDS (within 31 days of HIV diagnosis)

experience the negative outcome of viral rebound, suggesting a lesser ability to maintain optimal treatment outcomes consistently over time.

This study is subject to a number of limitations. First, the primary exposure of interest, as defined for this analysis (enrollment as of January 2011 in NYC HOPWA), may not suffice to capture the actual influence of these services on multiple HIV-related medical outcomes. Enrollment does not guarantee that services were actually received, nor does it indicate a particular 'dose' of the treatment (i.e., number and type of services, duration of services, prior HOPWA services history, quality of services, level of participation, etc.). Future analyses should determine whether there is a threshold level (or dose) of NYC HOPWA services, or a 
Table 2 HIV-related care outcomes by NYC HOPWA status, 2011

\begin{tabular}{|c|c|c|}
\hline & $\begin{array}{l}\text { NYC HOPWA clients } \\
N=1,357 \\
N(\%)\end{array}$ & $\begin{array}{l}\text { Random sample of other PLWHA } \\
N=13,489 \\
N(\%)\end{array}$ \\
\hline \multicolumn{3}{|c|}{ Retention in care ${ }^{\mathrm{a}}$} \\
\hline Yes & $1,296(94)$ & $11,127(82)$ \\
\hline No & $88(6)$ & $2,362(18)$ \\
\hline \multicolumn{3}{|c|}{ Viral suppression $^{\mathrm{b}}$} \\
\hline Yes & $1,035(78)$ & $10,077(82)$ \\
\hline No & 289 (22) & $2,251(18)$ \\
\hline \multicolumn{3}{|c|}{ Durable viral suppression $^{c}$} \\
\hline Yes & $818(84)$ & 7,688 (86) \\
\hline No & $174(16)$ & $1,292(14)$ \\
\hline \multicolumn{3}{|c|}{ Viral rebound $^{\mathrm{d}}$} \\
\hline Yes & $92(11)$ & $495(7)$ \\
\hline No & 735 (89) & $6,135(93)$ \\
\hline
\end{tabular}

Numbers in bold denote statistical significance at the 0.05 level. Data as reported to the NYC DOHMH by September 30, 2012

NYC HOPWA New York City Housing Opportunities for Persons with AIDS, PLWHA persons living with HIV/AIDS, $V L$ viral load

${ }^{a}$ Retention in care defined as having $\geq 2$ lab results $\geq 3$ months apart in 2011

b Viral suppression defined as having $\geq 1 \mathrm{VL} \leq 200$ copies/mL in 2011, among those with at least $1 \mathrm{VL}$ in 2011

${ }^{c}$ Durable suppression defined as having $\geq 2$ consecutive VLs $\leq 200$ copies/mL at least 2 weeks apart in 2011, among those with at least 2 VLs in 2011

${ }^{d}$ Viral rebound defined as having $\geq 1 \mathrm{VL}>200$ copies $/ \mathrm{mL}$ after $\geq 2$ VLs $\leq 200$ copies/mL at least 2 weeks apart in 2011, among those with at least 3 VLs in 2011 specific type or pattern of NYC HOPWA service utilization (RA, HPA and/or SPH), for which the evidence of program effectiveness becomes clearer or more consistent.

Second, we may not have fully controlled for measured variables in the construction of the propensity score. A substantial proportion of NYC HOPWA enrollees and PLWHA in the comparison group were concurrently enrolled in other local HIV public assistance programs for which DOHMH has client-level enrollment data. Thus, both groups received other services that may reflect level of need and could be expected to improve care outcomes. Information on reason for or duration, dose, and type of additional service exposures was not available, though, and incomplete control of these factors may have affected the construction of the propensity scores, introducing residual confounding of the effect of NYC HOPWA program enrollment. Also, residual confounding could have resulted from not fully accounting for baseline clinical and immunologic status, which was represented by a single indicator (last CD4 count as of the end of 2010).

Third, we were not able to account for unmeasured variables. Individual-level factors such as income, level of educational attainment, employment status, mental health status, hospitalizations, insurance status (i.e., private vs. public) and substance use history are not systematically and routinely reported to NYC DOHMH for surveillance purposes, and therefore were not captured in this comparison group analysis.

With regard to the inconsistent direction of findings on health outcomes in this sample, NYC HOPWA clients may

Table 3 Results of unmatched and matched logistic regressions of NYC HOPWA enrollment on measures of engagement in care, 2011

\begin{tabular}{|c|c|c|c|}
\hline & $N$ & Unmatched OR $(95 \% \mathrm{CI})$ & Full optimal match $\mathrm{OR}^{\mathrm{a}}(95 \% \mathrm{CI})$ \\
\hline Retention in care ${ }^{\mathrm{b}}$ & 14,468 & $3.06(2.45,3.81)$ & $2.97(2.35,3.74)$ \\
\hline Viral suppression $^{\mathrm{c}}$ & 13,652 & $0.80(0.70,0.92)$ & $0.92(0.79,1.08)$ \\
\hline Durable viral suppression $^{\mathrm{d}}$ & 9,972 & $0.79(0.66,0.94)$ & $0.85(0.70,1.03)$ \\
\hline Viral rebound ${ }^{\mathrm{e}}$ & 7,457 & $1.55(1.23,1.96)$ & $1.45(1.10,1.91)$ \\
\hline
\end{tabular}

Numbers in bold denote statistical significance at the 0.05 level. Data as reported to the NYC DOHMH by September 30, 2012

NYC HOPWA New York City Housing Opportunities for Persons with AIDS, VL viral load, $O R$ odds ratio, $C I$ confidence interval

${ }^{a}$ Matched for race/ethnicity, age at the end of 2011, sex, neighborhood-level poverty, transmission risk, country of origin, concurrent diagnosis (HIV \& AIDS), enrollment in other local HIV public assistance programs in 2011, and last CD4 count as of the end of 2010. Neighborhood-level poverty, based on ZIP code at HIV or AIDS diagnosis, represents the percent of residents living below the federally defined threshold for poverty, and is categorized as: 0 to $<10 \% ; 10$ to $<20 \% ; 20$ to $<30 \%$; and 30 to $100 \%$

${ }^{\mathrm{b}}$ Retention in care defined as having $\geq 2$ lab results $\geq 3$ months apart in 2011

c Viral suppression defined as having $\geq 1 \mathrm{VL} \leq 200$ copies/mL in 2011 , among those with at least 1 VL in 2011

d Durable suppression defined as having $\geq 2$ consecutive VLs $\leq 200$ copies/mL at least 2 weeks apart in 2011, among those with at least 2 VLs in 2011

e Viral rebound defined as having $\geq 1 \mathrm{VL}>200$ copies/mL after $\geq 2 \mathrm{VLs} \leq 200$ copies/mL at least 2 weeks apart in 2011, among those with at least 3 VLs in 2011 
have higher retention in care for reasons related to their assessed risk for suboptimal HIV outcomes. Perhaps NYC HOPWA clients returned to care more often because providers scheduled them at more frequent intervals, based on concerns about client health or compliance, or about losing contact with the most transient clients. Such reasons for higher visits frequency could explain the apparent contradiction of NYC HOPWA clients having more regular interaction with medical care, but a roughly equal rate of viral suppression and greater vulnerability to rebound [3739]. Sustained viral suppression also requires maintenance of a daily behavior, all of the time, rather than a single completed visit every several months. In this intent-to-treat analysis, in which intervention exposure varied substantially, differences in stability of housing and/or consistency of health maintenance behaviors during the follow-up period may partially explain inconclusive viral load results. Further investigation is warranted to elucidate the relationship of NYC HOPWA, and specific NYC HOPWA service types and doses, with HIV-related medical care outcomes.

Despite these limitations, this analysis has several strengths. It represents the first attempt to quantify engagement in care and treatment of individuals receiving HIV housing services, in comparison to a similar group in the larger HIV population. Additionally, NYC offers an ideal setting in which to examine program effectiveness, due to the large numbers of individuals living with HIV and using HIV-related housing services in the City, and due to named NYC HIV services reporting to the $\mathrm{DOHMH}$, as well as the mandatory named HIV surveillance reporting in New York State [19] yielding highly complete and linkable HIV-related outcomes data [37]. However, despite vigorous efforts to promote and evaluate housing stability as a means to improve access to care as recommended by the NHAS and DHHS [4, 7], optimal outcomes like durable viral suppression without viral rebound remain elusive to many PLWHA. Strengthening health care infrastructure to deliver services that focus on basic needs as well as HIV care and treatment remains critical to achieving an AIDS-free generation [40, 41].

Acknowledgments The authors would like to thank Kevin Konty and James Stark for their methodological contributions to the design of the analysis.

Conflict of interest The authors have declared that no competing interests exist.

Funding No current external funding sources for this study. The authors have no funding or support to report.

\section{References}

1. US Department of Housing and Urban Development. HOPWA 20: housing innovations in HIV care. Washington, DC: The Office of HIV/AIDS Housing; 2013.

2. RFP for Housing Opportunities for Persons with AIDS (HOPWA): Permanent supportive housing for persons living with HIV/ AIDS NYC DOHMH; 2012.

3. OKC HOPWA Program Overview. https://www.okc.gov/plan ning/homelessness/HOPWA\%20PROGRAM\%20OVERVIEW.pdf. Accessed 23 Oct 2014.

4. The White House Office of National AIDS Policy. National HIV/ AIDS strategy for the United States. Washington, DC; 2010.

5. Kidder DP, Wolitski RJ, Royal S, et al. Access to housing as a structural intervention for homeless and unstably housed people living with HIV: rationale, methods, and implementation of the housing and health study. AIDS Behav. 2007;11(6 Suppl): $149-61$.

6. The U.S. Department of Housing and Urban Development Office of Community Planning and Development. Introduction and overview of HUD Homeless Programs. https://www.hudex change.info/resources/documents/IntroandOverview_HUDPro grams_Presentation.pdf. Accessed 17 Oct 2014.

7. Sebelius Approves Indicators for Monitoring HHS-Funded HIV Services. 2012. http://blog.aids.gov/2012/08/secretary-sebeliusapproves-indicators-for-monitoring-hhs-funded-hiv-services.html. Accessed 8 April 2013.

8. CDC. Vital signs: HIV prevention through care and treatmentUnited States. MMWR. 2011;60(47):1618-23.

9. McNairy ML, El-Sadr WM. Antiretroviral therapy for the prevention of HIV transmission: what will it take? Clin Infect Dis. 2014;58(7):1003-11.

10. Ingle SM, May MT, Gill MJ, et al. Antiretroviral Therapy Cohort Collaboration. Impact of risk factors for specific causes of death in the first and subsequent years of antiretroviral therapy among HIV-infected patients. Clin Infect Dis. 2014;59(2):287-97.

11. Lennon CJ, Pellowski JA, White AC, et al. Service priorities and unmet service needs among people living with HIV/AIDS: results from a nationwide interview of HIV/AIDS housing organizations. AIDS Care. 2013;25(9):1083-91.

12. Kidder DP, Wolitski RJ, Campsmith ML, et al. Health status, health care use, medication use, and medication adherence among homeless and housed people living with HIV/AIDS. Am J Public Health. 2007;97(12):2238-45.

13. McAllister-Hollod L, Rojas J, Towe V et al. Evaluation of enhanced housing placement assistance for homeless persons living with HIV. NYC DOHMH unpublished data; 2013.

14. Royal SW, Kidder DP, Patrabansh S, et al. Factors associated with adherence to highly active antiretroviral therapy in homeless or unstably housed adults living with HIV. AIDS Care. 2009;21(4):448-55.

15. Wong MD, Cunningham WE, Shapiro MF, et al. HCSUS Consortium. Disparities in HIV treatment and physician attitudes about delaying protease inhibitors for nonadherent patients. J Gen Intern Med. 2004;19(4):366-74.

16. U.S. Department of Health and Human Services. Housing is health care: a guide to implementing the HIV/AIDS Bureau (HAB) Ryan White CARE Act Housing Policy. Washington, DC: Health Resources and Services Administration; 2001.

17. Wolitski RJ, Kidder DP, Pals SL, et al. Randomized trial of the effects of housing assistance on the health and risk behaviors of homeless and unstably housed people living with HIV. AIDS Behav. 2010;14(493-503):12. 
18. Messeri PA, Abramson DM, Aidala AA, et al. The impact of ancillary HIV services on engagement in medical care in New York City. AIDS Care. 2002;14(1):S15-29.

19. State of New York Laws. HIV Testing and Counseling. Amendment to New York State Public Health Law Article 21, Amendment of Part 63 of Title 10, Codes, Rules and Regulations of the State of New York (HIV/AIDS Testing, Reporting, and Confidentiality of HIV-related information), chap. 308. Albany: State of New York; 2010.

20. Centers for Disease Control and Prevention. Guidelines for national human immunodeficiency virus case surveillance, including monitoring for human immunodeficiency virus infection and acquired immunodeficiency syndrome. MMWR. 1999;48(RR-13):29-31.

21. Miller L, Arakaki L, Ramautar A, et al. Elevated risk for invasive meningococcal disease among persons with HIV. Ann Intern Med. 2014;160(1):30-7.

22. Torian LV, Xia Q. Achievement and maintenance of viral suppression in persons newly diagnosed with HIV, New York City, 2006-2009: using population surveillance data to measure the treatment part of "Test and Treat.". J Acquir Immune Defic Syndr. 2013;63(3):379-86.

23. Hall HI, Gray KM, Tang T, et al. Retention in care of adults and adolescents living with HIV in 13 U.S. areas. J Acquir Immune Defic Syndr. 2012;60(1):77-82.

24. Willis S, Castel AD, Ahmed T, et al. Linkage, engagement, and viral suppression rates among HIV-infected persons receiving care at medical case management programs in Washington, DC. J Acquir Immune Defic Syndr. 2013;64(Supp1):S33-41.

25. Xia, Q, Kobrak P, Wiewel E, Torian L. Late stage HIV Infection detection rate in New York City, 2004-2008. XIX International AIDS Conference. Washington, DC; 2012.

26. Terzian AS, Bodach SD, Wiewel EW, et al. Novel use of surveillance data to detect HIV-infected persons with sustained high viral load and durable virologic suppression in New York City. PLoS One. 2012;7(1):e29679.

27. Panel on Antiretroviral Guidelines for Adults and Adolescents. Guidelines for the use of antiretroviral agents in HIV-1-infected adults and adolescents. Department of Health and Human Services. http://aidsinfo.nih.gov/ContentFiles/AdultandAdolescentGL.pdf. Section Accessed 20 Aug 2013.

28. Austin PC. An introduction to propensity score methods for reducing the effects of confounding in observational studies. Multivar Behav Res. 2011;46(3):399-424.
29. Greenland S, Robins JM. Identifiability, exchangeability, and epidemiological confounding. Int J Epidemiol. 1986;15(3):413-9.

30. Rosenbaum PR, Rubin DB. Constructing a control group using multivariate matched sampling methods that incorporate the propensity score. Am Stat. 1985;39(1):33-8.

31. Lim SW, Singh T, Stazesky E, et al. Strengthening causal inference using optimal full matching: an empirical demonstration in a program evaluation. 140th APHA Annual Meeting. San Franscico, CA; 2012.

32. Normand SL, Landrum MB, Guadagnoli E, et al. Validating recommendations for coronary angiography following an acute myocardial infarction in the elderly: a matched analysis using propensity scores. J Clin Epidemiol. 2001;54:387-98.

33. Lim SW, Marcus SM, Singh TP, Harris TG, Seligson AL. Bias due to sample selection in propensity score matching for a supportive housing program evaluation in New York City. PLoS One. 2014;9(10):e109112.

34. Palepu A, Milloy MJ, Kerr T, Zhang R, Wood E. Homelessness and adherence to antiretroviral therapy among a cohort of HIVinfected injection drug users. J Urban Health. 2011;88(3):545-55.

35. Vital signs: HIV prevention through care and treatment-United States. MMWR. 2011;60(47):1618-23.

36. Wiewel E. NYC DOHMH Bureau of HIV/AIDS Prevention and Control. Personal communication; 2013.

37. Sabharwal CJ, Braunstein SL, Robbins RS, Shepard CW. Optimizing the use of surveillance data for monitoring the care status of persons recently diagnosed with HIV in NYC. J Acquir Immune Defic Syndr. 2014;65(5):571-8.

38. Kim TW, Kertesz SG, Horton NJ, Tibbetts N, Samet JH. Episodic homelessness and health care utilization in a prospective cohort of HIV-infected persons with alcohol problems. BMC Health Serv Res. 2006;6:19.

39. Sadowski LS, Kee RA, VanderWeele TJ, et al. Effect of a housing and case management program on emergency department visits and hospitalizations among chronically ill homeless adults: a randomized trial. JAMA. 2009;301(17):1771-8.

40. Valdiserri RO. Achieving an AIDS-free generation: it's the details that matter. Public Health Rep. 2012;127(6):563-4.

41. United States Interagency Council on Homelessness. Opening doors: federal strategic plan to prevent and end homelessness. 2010. http:// usich.gov/PDF/OpeningDoors_2010_FSPPreventEndHomeless.pdf. Accessed 17 Oct 2014. 